\title{
The confidential enquiry into maternal and child health (CEMACH)
}

\section{A $M$ Weindling}

\section{A review of the history of confidential enquiries}

T he Confidential Enquiry into Maternal and Child Health (CEMACH) was established in April 2003. It replaces CESDI (the Confidential Enquiry into Stillbirths and Deaths in Infancy) and CEMD (the Confidential Enquiry into Maternal Deaths); this gives it a truly perinatal focus, but its remit is now wider and includes all childhood death. This paper reviews the history of confidential enquiries, some of the principle findings of CEMACH's predecessors, and the methodology and aims of CEMACH.

\section{THE HISTORY OF CONFIDENTIAL ENQUIRIES}

The current system of confidential enquiries started in 1952, just four years after the inception of the NHS. Before that, maternal deaths were reported to the Ministry of Health on an ad hoc basis. ${ }^{1}$ The first report of CEMD covered 1952-54, capturing $77 \%$ of maternal deaths during that period. From 198587 onwards, a single report was published triennially for the whole of the United Kingdom. ${ }^{2}$ The purposes of the CEMD were to assess the main causes of maternal deaths and, through the identification of avoidable causes, to reduce maternal morbidity and mortality by recommending improvements in clinical care and service provision; it also indicated directions for future research and audit.

CESDI was established in 1992, after the Department of Health directed that the 14 regions of England should undertake perinatal mortality surveys. CESDI's remit was to improve understanding of the causes of death in late fetal life and infancy-that is, from 20 weeks post-conception to one year after birth. Its aim was to reduce mortality by identifying suboptimal patterns of practice and service provision related to those deaths and to make recommendations for improvement. Combining CEMD and CESDI, CEMACH retains this regional organisation and these overall aims.

There are two other national confidential enquiries: the National Confidential Enquiry into Perioperative Deaths (NCEPOD) and the Confidential Enquiry into Suicides and Homicides (CISH). All the confidential enquiries now fall under the umbrella of the National Institute of Clinical Excellence (NICE).

All confidential enquiry reports describe the conclusions of audits of their work by those involved in that field. The reports have been authoritative and have influenced clinical practice. Their frequency of publication is determined by the rate of occurrence of the events described. In the United Kingdom there are an estimated 957500 pregnancies a year* and between 300 and 400 maternal deaths a year (giving a maternal mortality rate of 11.4 deaths per 100000 maternities over the most recent period reported, 1997-99; see box 1): ${ }^{3}$ reports on maternal deaths are published every three years. The scale of the work undertaken by CESDI was quite different. About 10000 deaths occur annually between 20 weeks gestation and 1 year of age in England, Wales, and Northern Ireland (644 940 live births and stillbirths in 1999; perinatal mortality rate 7.9 per 1000 live births) and reports are published annually. It is of course not possible to have an enquiry about all these deaths and CESDI has always had a rolling programme, identifying specific criteria for detailed confidential enquiry. Table 1 summarises some of CESDI's previous work programmes.

*The figure combines pregnancies that resulted in a live birth at any gestation or a stillbirth at or after 24 weeks (known as "maternities" of which there are about 708000 a year), legal terminations, spontaneous abortions, and ectopic pregnancies, and is likely to be an underestimate. desire to improve care and a great many people are involved. ${ }^{2}$ CEMACH has a central office with a permanent staff of six and there are managers in each of the regions of England and Wales, who are responsible for individual enquiries. Each enquiry panel for a death that fulfils pre-set criteria comprises clinicians from relevant specialties, who are independent of the hospital where the patient died and who are unaware of the clinicians concerned with the patient's care-one of the regional managers' tasks is to ensure that the case notes are anonymised. The results of these enquiries are then collated.

CESDI's early projects often lacked controls and denominator information, which limited their interpretation and generalisability. ${ }^{3}$ However, the study of Sudden Unexpected Deaths in Infants, ${ }^{45}$ the Antepartum Term Stillbirth Study, ${ }^{6}$ and the study on babies at 27 and 28 weeks gestation ${ }^{6}$ have included information about controls. Other CESDI projects have used a focus group methodology (for example, reports on shoulder dystocia, ${ }^{6}$ ruptured uterus, ${ }^{6}$ planned home delivery, ${ }^{6}$ anaesthetic complications and delays, ${ }^{8}$ breech presentation, ${ }^{8}$ and the onset of labour (all undertaken in 1994-95) and stillbirths (undertaken in 1996-97) ${ }^{9}$ ).

\section{SOME FINDINGS OF CEMACH'S PREDECESSORS}

The CEMD reports showed a fall in maternal deaths due to abortion from 153 in 1952-54 to one in 1994-99, attributable to the legalisation of abortion. Between the same periods, maternal deaths from haemorrhage fell from 188 to nine because of oxytocic injections, ultrasound diagnosis of placenta praevia, and improved intensive care. Death due to thromboembolism, which remains an important cause of maternal mortality, fell from 138 to 46 over this same 40 year period. ${ }^{10}$ After 1993, there was improved case ascertainment through linking data with that provided by the Office for National Statistics. Table 2 summarises major causes of maternal deaths and their rates. ${ }^{11}$

Table 1 Some CESDI work programmes.

\begin{tabular}{|c|c|c|}
\hline Enquiry topic & Year of study & Annual report in which findings reported \\
\hline Intrapartum related deaths $>2.5 \mathrm{~kg}$ & 1993 & 2nd \\
\hline Intrapartum related deaths $>1.5 \mathrm{~kg}$ & 1994-95 & 4 th \\
\hline $\begin{array}{l}\text { "Explained" sudden unexpected deaths } \\
\text { in infancy }\end{array}$ & $1993-96$ & 5 th \\
\hline "1 in $10^{\prime \prime}$ sample of all deaths $>1 \mathrm{~kg}$ & 1996-97 & 6 th \\
\hline All deaths $4 \mathrm{~kg}$ and over & 1997 & 6 th \\
\hline Case control studies & & \\
\hline Sudden unexpected deaths in infancy & 1993-96 & $3 r d$ and 5th and the CESDI SUDI studies \\
\hline Antepartum term stillbirths & 1995 & 5 th \\
\hline Project $27 / 28$ & 1998-2000 & 8th \\
\hline
\end{tabular}




\section{Box 1 Classification of maternal deaths}

Maternal deaths are defined as deaths of women while pregnant or within 42 days of delivery, miscarriage, or termination of pregnancy, from any cause related to or aggravated by the pregnancy or its management, but not from accidental or incidental causes. Maternal deaths are classified as:

- Direct (deaths resulting from obstetric complications of the pregnant state (pregnancy, labour, and puerperium), from interventions, omissions, incorrect treatment, or from a chain of events resulting from any of the above).

- Indirect (deaths resulting from previous existing disease or diseases that developed during the pregnancy and not due to direct obstetric causes but aggravated by the physiological effect of pregnancy).

- Late (deaths occurring between 42 days and one year after termination of pregnancy, miscarriage, or delivery that are due to Direct or Indirect maternal causes.

- Coincidental (previously known as Fortuitous) deaths (those due to unrelated causes which happen to occur in pregnancy or the puerperium).

In $1994-95,52 \%$ of 873 deaths related to intrapartum events were found to have received suboptimal care and the intrapartum related mortality rate was 0.95 per 1000 live and stillbirths; ${ }^{12}$ by 1999, the intrapartum related mortality rate had decreased to $0.62 .{ }^{9}$ There is, however, no room for complacency. The 1999 CESDI report warned about a failure to recognise that fetal growth failure was a precursor of many stillbirths. It was necessary to repeat recommendations that had been made in 1997 and 1998: there is a need to improve the quality of maternity records to enable clear identification of risk factors and appropriate management plans during the ante- and intra-partum periods.

Several CESDI reports have commented on the use of fetal monitoring. The 1997 CESDI report showed a failure of use and/ or interpretation of the cardiotocograph (CTG) in more than half of deaths that occurred intrapartum. ${ }^{12}$ A focus group on the ruptured uterus reported that
$26 \%$ of comments on substandard care related to fetal monitoring. ${ }^{13}$ The following year, a "4 kg and over" survey also found deficiencies in the interpretation of CTGs. ${ }^{14}$ CESDI consequently recommended that every hospital offering intrapartum care should train and update staff regularly in the use of CTGs, and standards were developed: $:^{15-17}$

- Basic provision of electronic fetal monitoring (EFM) facilities should be 2-4 machines per 1000 deliveries.

- A guideline on the use of EFM should be available in every unit.

- Continuous EFM should be used in selected high risk pregnancies.

- If EFM is used, fetal blood sampling should be available.

- In situations of suspected fetal compromise, umbilical cord $\mathrm{pH}$ should be measured at delivery.

One of CESDI's last projects was "Project $27 / 28$ - An enquiry into the quality of care and its effect on the survival of babies born at 27-28 weeks". ${ }^{7}$ This major piece of work aimed to identify patterns of practice and service provision that were considered to have contributed to the deaths of babies born at 27 and 28 weeks gestation born between 1 September 1998 and 31 August 2000. It collected denominator data, set out standards, and used a case-control study approach to make recommendations for the better care of these very vulnerable infants. During the study period the neonatal mortality rate in this group was $12 \%$. The Project made 16 recommendations for standards at a national and commissioning level and 64 at Trust level. These included recommendations about:

- Avoiding super-ovulation and multiple pregnancies when assisted reproductive techniques are used.

- Ensuring that units have a system to identify mothers who are at risk of preterm delivery at booking and during antenatal care and that these mothers should receive appropriate consultant care.

- A specialist high risk team to manage the labour and delivery of the baby of 28 weeks and less.

- Appropriate guidelines, which should include communication issues between professionals, the management of infection in the mother and baby, and thermal, respiratory, and cardiovascular support of the baby.

- Managed clinical networks and appropriate staffing levels.

Both the CEMD and CESDI have drawn attention to public health messages. In 1996, CESDI promoted key messages from the SUDI (Sudden Unexpected Deaths

Table 2 Major causes of maternal deaths per million maternities notified to the CEMD: United Kingdom 1985-99"1

\begin{tabular}{|c|c|c|c|c|c|}
\hline & $1985-87$ & $1988-90$ & 1991-93 & $1994-96$ & $1997-99$ \\
\hline \multirow{2}{*}{\multicolumn{6}{|c|}{ Direct causes }} \\
\hline & & & & & \\
\hline Thrombosis and thromboembolism & 14.1 & 14.0 & 15.1 & 21.8 & 16.5 \\
\hline Pregnancy induced hypertension & 11.9 & 11.4 & 8.6 & 9.1 & 7.1 \\
\hline Haemorrhage & 4.4 & 9.3 & 6.5 & 5.5 & 3.3 \\
\hline Amniotic fluid embolism & 4.0 & 4.7 & 4.3 & 7.7 & 3.8 \\
\hline Early pregnancy & $7.9^{*}$ & 7.6 & 5.2 & 6.8 & 8.0 \\
\hline Sepsis & 4.4 & 5.5 & 6.4 & 6.4 & 6.6 \\
\hline Uterine trauma & 2.6 & 1.3 & 1.7 & 2.3 & 1.0 \\
\hline Other & 9.3 & 5.9 & 4.3 & 0.9 & 2.3 \\
\hline Anaesthetic & 2.6 & 1.7 & 3.5 & 0.5 & 1.4 \\
\hline \multicolumn{6}{|l|}{ Indirect causes } \\
\hline Cardiac & 10.1 & 7.6 & 15.9 & 17.7 & 16.5 \\
\hline Psychiatric $†$ & - & - & - & 4.1 & 7.1 \\
\hline Other & 37.0 & 31.0 & 27.0 & 39.1 & 35.3 \\
\hline Malignancies $\ddagger$ & - & - & - & - & 5.1 \\
\hline Total direct and indirect causes & 98.2 & 100.1 & 98.1 & 121.9 & 114.0 \\
\hline Coincidental causes & 11.3 & 16.5 & 19.9 & 16.4 & 10.8 \\
\hline Late causes & - & 20.3 & 19.9 & 32.8 & 50.3 \\
\hline
\end{tabular}

Including sepsis in early pregnancy.

+Until 1993-96 counted as "coincidental".

fUntil 1997-99 not classified separately. 


\section{Box 2 Key health messages from the SUDI studies"}

\section{Back to sleep}

Babies should be put down to sleep lying on their backs, unless there is a substantial medical reason not to do so. Sleeping on the back is preferable to sleeping on the side, and sleeping on the front should be avoided.

\section{Feet to foot; head uncovered}

Babies should sleep in such a way that their head does not become uncovered during sleep. This is most easily achieved by putting a baby to sleep with his or her feet close to or touching the foot of the cot. Blankets are preferred to duvets, and should be tucked in so that the baby's head is exposed and uncovered without a hat.

Not too hot

Although it is important to prevent a baby becoming cold, becoming too hot is also a danger. Room heating is not required at night except when the weather is very cold. Babies' bedrooms should be at a temperature overnight which is comfortable for a lightly clothed adult (usually $16-20^{\circ} \mathrm{C}$ ).

\section{Smoke-free zone}

Cigarette smoking in pregnancy and around babies increases the risk of cot death. Although giving up would be the best option, a baby will be partly protected if his or her sleeping place is regarded as a smoke-free zone, whether the baby is asleep there or not.

\section{Prompt medical advice}

The risk of cot death may be reduced by seeking prompt medical advice for babies who become unwell, particularly those with a raised temperature, breathing difficulties and who are less responsive than usual. A proportion may have acute infections amenable to treatment.

\section{Bed sharing for comfort, not sleep}

While it is likely to be beneficial for parents to take their baby into bed with them to feed or comfort, it is preferable to place the baby back into a cot to sleep. This is especially important if the parents smoke or have consumed alcohol. in Infancy) studies (box 2). ${ }^{19}$ In 1998, the CEMD gave clear advice on the correct use of seat belts by pregnant women (box 3$).^{10}$

A review of trends in reproductive epidemiology by the CEMD has shown a steady increase in the proportion of deliveries by caesarean section: $3 \%$ in the 1950 s, $10 \%$ in the early 1980 s, $15 \%$ in $1994-95$, and over $18 \%$ in $1997-99 .^{18}$ This increase has implications both for the health of mothers and for the healthy survival of their children. The most recent CEMD publication highlighted 20 -fold increased mortality rate among the most disadvantaged. ${ }^{3}$ These issues, which cut across the interests of different groups of patients, are areas that CEMACH will be able to address.

\section{THE FUTURE}

The CEMD and CESDI were previously managed by the Department of Health. In 1996, the management of CESDI was taken over by a consortium of royal colleges. Now NICE provides most of the funding. However, the profession still runs $\mathrm{CEMACH}$ and its management board comprises members nominated by the Royal Colleges of Paediatrics and Child Health (RCPCH), Obstetrics and Gynaecology (RCOG), Pathology (RCPath), Midwives (RCM), Anaesthetics (RCA), and the Faculty of Public Health.

CEMACH will continue to review the causes of deaths related to pregnancy and those occurring during infancy, but will also include children up to the age of 16 years. Furthermore, as the change in title implies, the new enquiry will be concerned with morbidity as well as mortality.

There will be three sections, each headed by a National Advisory Group, which will advise on the content of the programme of work. One section will continue the work of the CEMD, considering the problems of pregnancy. The next edition of the triennial report, covering the period 2000-02 is being prepared and data are being collated for 2003 05 report. The last CEMD report identified suicide as a leading cause of maternal death-there were 28 such deaths, compared with 35 due to thrombosis and thromboembolism and 15 due to pregnancy induced hypertension. This is the sort of issue where work undertaken by the new Confidential Enquiry might be linked with that of an existing one, CISH.

The second section of CEMACH will take on the work of CESDI: the present programme considers the problems of the diabetic mother and her infant, using a case-control approach. Diabetes is the most common pre-existing medical disorder complicating pregnancy in the United Kingdom, affecting approximately four per 1000 pregnancies. The St Vincent Declaration ${ }^{20}$ stated that every diabetic pregnancy should have a near normal outcome, but in the UK, where the background perinatal mortality rate is $7.9 / 1000$, the perinatal mortality rate of pregnancies complicated by maternal diabetes varies between 36.1 and 42.8 per $1000 .^{21-23}$ A survey by CEMACH has found that facilities available to pregnant diabetic women appear to be variable throughout the UK. CEMACH has set standards, and appointed panel chairs; the confidential enquiries are about to start.

The third of CEMACH's sections will consider the problems of childhood. This latter task is potentially broad and challenging. The precise area has not yet been decided, but it is likely to cross professional boundaries, perhaps involving social services and education. The methodology will continue to be based on confidential enquiries around individual cases and it will be case-controlled. Whatever the precise problems of childhood that are to be considered, CEMACH is determined to make a difference to the lives of children. Many of the CESDI and CEMD reports are available on the CEMACH website (www.cemach.org.uk).

\section{Arch Dis Child 2003;88:1034-1037}

Correspondence to: Professor A M Weindling, Department of Child Health, University of Liverpool, Neonatal Unit, Liverpool Women's Hospital, Crown St, Liverpool L8 7SS, UK; a.m.weindling@liv.ac.uk

\section{REFERENCES}

Department of Health, Welsh Office, Scottish office Department of Health, Department of Health and Social Services, Northern Ireland. Why mothers die. Report on confidential enquiries into maternal deaths in the United Kingdom 19941996. Her Majesty's Stationery Office, 1998.

2 Macfarlane A. Enquiries into maternal deaths during the 20th century. In: Why Mothers Die 1997-1999. The Confidential Enquiry into Maternal Deaths in the United Kingdom. The RCOG Press, 2001.

3 RCOG. Why mothers die 1997-1999. The Confidential Enquiry into Maternal Deaths in the United Kingdom. The RCOG Press, 2001.

4 Blair PS, Fleming PJ, Smith I, et al. Babies sleeping with parents: case-control study of factors

\section{Box 3 Recommendations for use of seat belts in pregnancy ${ }^{10}$}

All pregnant women should be given advice about the correct use of seat belts as soon as their pregnancy is confirmed:

- Above and below the bump, not over it.

Three-point seat belts should be worn throughout the pregnancy, with the lap strap placed as low as possible beneath the "bump", lying across the thighs with the diagonal shoulder strap above the bump lying between the breasts. The seat belt should be adjusted to fit as snugly as comfortably possible and, if necessary, the seat should be adjusted to enable the seat belt to be worn properly. 
influencing the risk of sudden infant death syndrome. BMJ 1999;319:1457-62.

5 Department of Health. Sudden unexpected deaths in infancy The CESDI SUDI Studies. London: The Stationery Office, 2000.

6 Maternal and Child Health Research Consortium. Confidential Enquiry into Stillbirths and Deaths in Infancy: 5th Annual Report, 1 January-31 December 1996. London: Maternal and Child Health Research Consortium, 1998:85-92.

7 Macintosh M, ed. CESDI. Project 27/28. An enquiry into quality of care and its effect on the survival of babies born at 27-28 weeks. London: The Stationery Office, 2003.

8 Maternal and Child Health Research Consortium. Confidential Enquiry into Stillbirths and Deaths in Infancy: 7th Annual Report, 1 January-31 December 1998. London: Maternal and Child Health Research Consortium, 2000:81-6.

9 Maternal and Child Health Research Consortium. 8th Annual Report. Confidential Enquiry into Stillbirths and Deaths in Infancy. London: Maternal and Child Health Research Consortium, 2001.

10 Anon. Why mothers die. Report on confidential enquiries into maternal deaths in the United Kingdom 1994-1996. London: The Stationery Office, 1998.
11 RCOG. Why mothers die 1997-1999. The confidential enquiries into maternal deaths in the United Kingdom. RCOG Press, 2001

12 Maternal and Child Health Research Consortium. Confidential Enquiry into Stillbirths and Deaths in Infancy: 4th Annual Report, 1 January-31 December 1995. London: Maternal and Child Health Research Consortium, 1997.

13 Maternal and Child Health Research Consortium. Confidential Enquiry into Stillbirths and Deaths in Infancy: 5th Annual Report, 1 January-31 December 1996. London: Maternal and Child Health Research Consortium, 1998.

14 Maternal and Child Health Research Consortium. Confidential Enquiry into Stillbirths and Deaths in Infancy: 4th Annual Report, 1 January-31 December 1995. London: Maternal and Child Health Research Consortium, 1997.

15 Royal College of Obstetricians and Gynaecologists and Royal College of Midwives. Towards safer childbirth: minimum standards for the organisation of labour wards. Report of a joint working party. London: RCOG Press, 1999:1-31.

16 The National Health Service (Clinical Negligence Scheme) (Amendment) Regulations 1997. London: The Stationary Office, 1997.

17 Steer PJ, Danielian P. Fetal distress in labour. In: James DK, Steer PJ, Wesner CP, Gonik B, eds.
High risk pregnancy: management options London: WB Saunders, 1999

18 Botting B. Trends in reproductive epidemiology and women's health. In: Why mothers die 19971999. The confidential enquiries into maternal deaths in the United Kingdom. RCOG Press, 2001

19 DoH. Confidential Enquiry into Stillbirths and Deaths in Infancy. 3rd Annual Report, 1 January-31 December 1994. The Department of Health, 1996, 1997.

20 Workshop Report. Diabetes care and research in Europe: the St Vincent Declaration. Diabet Med 1990:7:360.

21 Hawthorne G, Robson S, Ryall EA, et al., on behalf of the Northern Diabetic Pregnancy Audit. Prospective population based survey of outcome of pregnancy in diabetic women; results of the Northern Diabetic Pregnancy Audit, 1994. BM 1997;315:279-81.

22 Casson IF, Clark CA, Howard CV, et al. Outcomes of pregnancy in insulin dependent diabetic women: results of a five year population cohort study. BMJ 1997:315:275-8.

23 Hadden DR, McKane CR, Traub Al, on behalf of the Northern Ireland Diabetes Study group. Tenyear outcome of diabetic pregnancy in Northern Ireland: the case for centralization. Diabet Med 1998;15(suppl 1):S16.

\section{NEWS AND NOTES FROM THE UK}

\section{Care in the community}

think that she must be about $145 \mathrm{~cm}$ tall, perhaps $40 \mathrm{~kg}$, and about 60 years old. She might have been taller before, but now her legs bow and her back is hunched over. She's dressed in dirty, but not filthy, clothes which are nearly, but not yet, rags. However, none of these features are what you'd notice first about her. In fact, at first you don't see her diminutive figure at all-you hear her, from a good block or two away, because she's playing a drum.

The drum, supported by a strap around her neck looks fairly new and well cared for. Unlike the tin drum my grandad gave me for Christmas when I was five-thus endearing both him and me to my parents - this is a real drum, a cylinder with the same depth as diameter, real resonance and a deep, booming note.

The rhythm is strictly $2 / 2$ march. No complex quickstep of waltz here; no pretentious $5 / 4$ or fussy $6 / 8$ - just $2 / 2$, because that is the way she is walking. As I say, you can hear her from a block or two away, giving you enough time to work through "What on Earth?...", then "Maybe it's...", then "No it can't be...", and finally "Well, it really is!" When she gets really close you can tell that she's also singing, if you can describe a monotonal "La, la, la", in time with the beat of the drum singing.

If she spots you watching she'll pause, smile a broad smile with not many teeth, and give you a burst of drumming at a faster rate-not, for the moment, constrained by her walking pace.

The deal is that you give her a few pence for her playing and she goes away. Except that she is so obviously enjoying her playing that you are reluctant for her to leave; it is such a simple-but noisy-pleasure. The cynic would have it that she is playing to be a nuisance, so that you give her money to stop disturbing you. Her eyes, her slurred speech, her apparent difficulty hearing, and her childish laughter tell a different story: That she's probably enjoying this, probably a good deal more than you or I enjoy most of the things that we do. If you do a little dance with her metronomic beat, she'll laugh fit to cry, as if you've just told the world's funniest joke, or passed wind on live television.

This is a real live case of care in the community. Only here you get to choose if you are going to be a NIMBY-Not In My Back Yard-by paying just a few pence a day. You don't worry yourself about where she sleeps, or washes or eats, because she seems pretty happy, doesn't she?

An evil thought enters my mind. I see the consequences of (don't) care in the community coming home to roost, in Downing Street in the late eighties, where those policies were

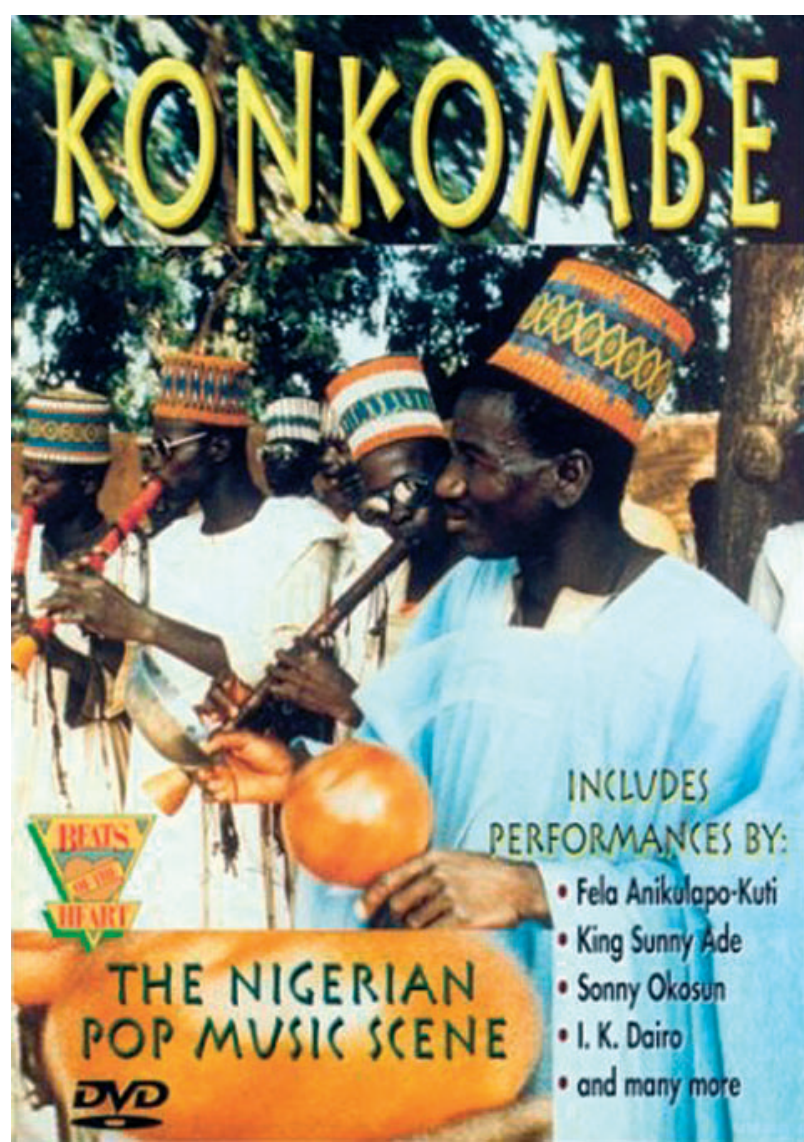

engineered. I see a hundred, no, a thousand of these ladies wandering by each day, each with a voice in the shape of a drum, each pounding out their own happy rhythm.

A drum isn't the same as a voice in a democracy, but it can be a lot of fun as this lady has shown me. The lingering questions remain, however. Where on earth did she get such a good drum, and where can I get hold of a job lot?

I D Wacogne lan Wacogne is a consultant in general paediatrics at Birmingham Children's Hospital 


\section{PostScript}

\section{LETTERS}

\section{Chronic urticaria and coeliac disease}

We appreciated the paper by Levy et al published in this journal in June 2003.

A number of the cases of chronic urticaria in children appear to be of unknown aetiology, and experiences such as the one reported by the authors indicate an autoimmune origin.

In our opinion the model of association between thyroiditis and chronic urticaria may apply to the association between coeliac disease and chronic urticaria as well Remarkably, Levy et al described a coeliac child with both chronic urticaria and autoimmune thyroiditis. In the literature, reports of at least four other cases of association between chronic urticaria and coeliac disease that improved after a gluten-free diet have been found,,$^{2-5}$ together with a report of a case of a coeliac 11 year old girl with chronic urticaria unresponsive to the diet. ${ }^{6}$

Our experience confirms that chronic urticaria may be associated with coeliac disease.

We tested 32 children and adolescents with idiopathic chronic urticaria for tissue transglutaminase antibodies. HLA typing was performed in 25 of these patients; 10 tested positive for the typical coeliac aplotype DQ2 DQ8. Three of 10 tested positive for tTG. None of the HLA negative children tested positive for tTG. In these three children a small bowel biopsy confirmed coeliac disease, and al showed an improvement or a resolution of the urticaria with a gluten-free diet.

Some evidence suggests that the duration of exposure to gluten in coeliac subjects is related to the risk of developing other autoimmune diseases. ${ }^{7}$ The hypothesis is that in coeliac disease the decrease of the immunological stimulus with the diet may decrease the production of other autoantibodies. This could possibly explain the improvements described after the adoption of a gluten-free diet in subjects with subclinical coeliac disease associated with chronic urticaria.

Therefore, even if this association is rare, we think that it is important to extend the field of investigation in the area of autoimmunity, screening for coeliac disease all subjects affected by chronic urticaria of unknown origin. This recommendation is strengthened by the consideration that the diet for coeliac disease could help their urticaria to improve, and may prevent the development of other types of autoimmune disorders.

R Meneghetti, T Gerarduzzi, E Barbi, A Ventura Istituto per I'Infanzia Burlo Garofalo, Trieste, Italy; ebarbi@libero.it

\section{References}

1 Levy Y, Segal N, Weintrob N, et al. Chronic urticaria: association with thyroid autoimmunity. Arch Dis Child 2003:88:517-19.

2 Hautekeete ML, De Clerck LS, Stevens WJ. Chronic urticaria associated with coeliac disease. Lancet 1987; 17:157.

3 Liutu M, Kalimo K, Uksila J, et al. Etiologic aspects of chronic urticaria. Int J Dermatol 1998;37:515-19.

4 Gallo C, Vighi G, Schroder J, et al. Chronic urticaria atopic dermatitis and celiac disease. Am J Gastroenterol 1992:87:1684.

5 Scala E, Giani M, Pirrotta L, et al. Urticaria and adult celiac disease. Allergy 1999;54:1008-9.

6 Levine A, Dalal I, Bujanover Y. Celiac disease associated with familial chronic urticaria and thyroid autoimmunity in a child. Pediatrics 1999; 104:e25

7 Ventura A, Magazzu G, Greco L. Duration of exposure to gluten and risk for autoimmune disorders in patients with celiac disease. Gastroenterology 1999;115:297-303.

\section{Vitamin B-12 in Crohn's disease} patients with small bowel surgery

Vitamin B-12 is absorbed from the terminal ileum, which is a commonly affected segment of gut in Crohn's disease. Its absorption may be compromised in these children secondary to inflammatory lesions, ileal bacterial overgrowth, or mucosal damage caused by reflux of bacteria and surgical resection. ${ }^{1}$ Of these surgical resection of large segments of term inal ileum remains the most important cause of B-12 malabsorption in such patients. Prolonged depletion leads to megaloblastic anaemia and ultimately neuropathy and myelopathy. Therefore, diagnosis and treatment of vitamin B-12 malabsorption in patients with Crohn's disease and smal bowel/ileal resection is of great importance.

There is a paucity of published paediatric data on vitamin B-12 absorption after resection of the ileum in childhood. Valman and Roberts observed impaired absorption of vitamin B-12 in 7 of 10 infants and children who had resection of $>45 \mathrm{~cm}$ of ileum. Absorption was however normal in 2 of 10 children who had $15 \mathrm{~cm}$ or more terminal ileum remaining. Impaired B-12 absorption after significant $(>60-180 \mathrm{~cm})$ ileal resection may be permanent; however in children, adaptation of the remaining small bowe may result in restoration of its absorption several years after ileal resection.

Our anecdotal experience and communication with other paediatric gastroenterology centres in the UK suggested that there is no common management strategy regarding B-12 supplementation after ileal resection. We, therefore, retrospectively examined in our own unit the impact of small bowel surgery on vitamin B-12 levels in 18 children with ileal resection secondary to Crohn's disease over a period of 10 years. All patients except one had normal or low mean corpuscular volume and mean corpuscular concentration throughout their follow up before and after surgery. Median age at surgery was 15 years. Nine children had $<30 \mathrm{~cm}$ of ileal resection and eight children $30-50 \mathrm{~cm}$ of terminal/distal ileum resected. Only one patient needed $>70 \mathrm{~cm}$ of ileal resection. None of these children were observed to have low vitamin B-12 levels before or after small bowel surgery (for $1-8$ years after surgery).

Our review of this small case series further highlights the significance of as yet unanswered question of vitamin B-12 supplementation in this group of children. As clinical and haematological B-12 deficiency may take several years to develop, serum B-12 levels alone may not be sufficient to decide about the need for its supplementation and regular formal B-12 absorption tests may be required. We feel that a large multicentre prospective cohort study is required to evaluate the need for regular monitoring of vitamin B-12 levels, its absorption tests, and the need for supplementation in children with Crohn's disease needing small bowel surgery.

M Ahmed, H R Jenkins

Department of Paediatric Gastroenterology, University Hospital of Wales, Heath Park, Cardiff CF14 4XW

doi: $10.1136 /$ adc. 2003.035527

Correspondence to: Dr H R Jenkins, Consultan Paediatric Gastroenterologist, Department of Child Health, University Hospital of Wales, Cardiff CF14 4XW, UK Huw.Jenkins@CardiffandVale.wales.nhs.uk

\section{References}

1 Behrend C, Jeppesen PB, Mortensen PB. Vitamin B-12 absorption after ileorectal anastomosis for Crohn's disease: effect of ileal resection and time span after surgery. Eur J Gastroenterol Hepatol 1995:7:397-400.

2 Valman HB, Roberts PD. Vitamin B12 absorption after resection of ileum in childhood. Arch Dis Child 1974;49:932-5.

3 Ooi BC, Barnes GL, Tauro GP. Normalization of vitamin B-12 absorption after ileal resection in children. J Paediatr Child Health

1992;28:168-71.

\section{CORRECTION}

doi: 10.1136/adc.2003.043679corr

We would like to apologise for a typing error in the paper by A M Weindling, which was published in the December 2003 issue (Arch Dis Child 2003;88:1034-37). In Box 2 the first sentence under the heading 'Feet to foot; head uncovered' should read: Babies should sleep in such a way that their head does not become covered during sleep. 